\title{
Development of Prototype Laboratory Setup for Selective Detection of Ethylene Based on Multiwalled Carbon Nanotubes
}

\author{
J. Kathirvelan ${ }^{1}$ and R. Vijayaraghavan ${ }^{2}$ \\ ${ }^{1}$ School of Electronics Engineering (SENSE), VIT University, Vellore 632 014, India \\ ${ }^{2}$ School of Advanced Sciences (SAS), VIT University, Vellore 632 014, India \\ Correspondence should be addressed to R. Vijayaraghavan; rvijayaraghavan@vit.ac.in
}

Received 12 June 2014; Accepted 16 October 2014; Published 6 November 2014

Academic Editor: Ignacio R. Matias

Copyright (c) 2014 J. Kathirvelan and R. Vijayaraghavan. This is an open access article distributed under the Creative Commons Attribution License, which permits unrestricted use, distribution, and reproduction in any medium, provided the original work is properly cited.

\begin{abstract}
We report here a prototype laboratory setup for detecting ethylene $\left(\mathrm{C}_{2} \mathrm{H}_{4}\right)$ in ppm level employing a sensor made of multiwalled carbon nanotubes of $40 \mathrm{~nm}$ average tube diameter. The proposed reversible chemoresistive ethylene sensor is fabricated using Kapton as the substrate onto which carbon nanotubes are coated using thick film technology. IDT silver electrodes are printed using piezo head based ink-jet printing technology. The increases in electrical resistance of the sensor element are measured on exposure to ethylene for different ethylene concentrations using a potentiostat and data acquisition system. The increase in resistance of the calibrated sensor element on exposure to ethylene (analyte) is about $18.4 \%$ at room temperature for 50 ppm ethylene concentration. This change is reversible. Our sensor element exhibits a better performance than those reported earlier (1.8\%) and it has got the rise and fall time of $10 \mathrm{~s}$ and $60 \mathrm{~s}$, respectively. It could be used for testing the ripening of fruits.
\end{abstract}

\section{Introduction}

Ethylene (IUPAC: ethene) is a small hydrocarbon gas coming under the family of alkenes. It is naturally occurring as a gaseous phytohormone in plants [1], but it can also occur as a result of combustion and other processes. Fruits will release ethylene as ripening begins by means of biosynthesis [2]. Apples, pears, bananas, and mangoes are some of the fruits that release ethylene while ripening [2,3]. Ethylene is responsible for the changes in texture, softening, color, and other processes involved in ripening [2]. The amount of ethylene concentration liberated from the fruits can indicate the level of fruit ripening and also measurement of ethylene is inevitable during the postharvest of the fruits and also during the transportation of the fruits in order to avoid overripening. The measurement of ethylene in fruits is also required to discriminate the type of ripening as fruits are also ripened by artificial ripening methods [3] which are not acceptable for consumption.

The existing techniques for measurement of ethylene are gas chromatographs, Fourier Transform, infrared spectroscopy, and electrochemical sensors which are laboratory based analytical methods and are expensive. To overcome the limitations of the existing analytical techniques a simple and cost effective sensor device needs to be developed. Towards this end a novel reversible chemoresistive ethylene gas sensor developed using multiwalled carbon nanotubes is reported here in addition to already reported electrochemical techniques [4].

Single walled carbon nanotube (SWNT) discovered by Iijima and Ichihashi [5] attracted much attention due to its extraordinary properties. After the discovery of carbon nanotubes in 1991 by Iijima and Ichihashi an extensive research work was carried out to explore their unique electrical, physical, mechanical, and chemical properties for developing high performance devices [6]. The unique properties of carbon nanotubes made them attractive for novel applications in the field of gas sensing [7-9].

The CNTs can operate even at room temperature which is optimal for developing ultra low power, wearable battery operated devices $[10,11]$. Carbon nanotubes are preferred for gas sensing $\left(\mathrm{NH}_{3}, \mathrm{CH}_{4}\right.$, and $\left.\mathrm{CO}_{2}\right)$ due its tubular structure with large surface to volume ratio, which provides plenty of sites for gaseous molecules to adsorb [12-14]. The adsorption 


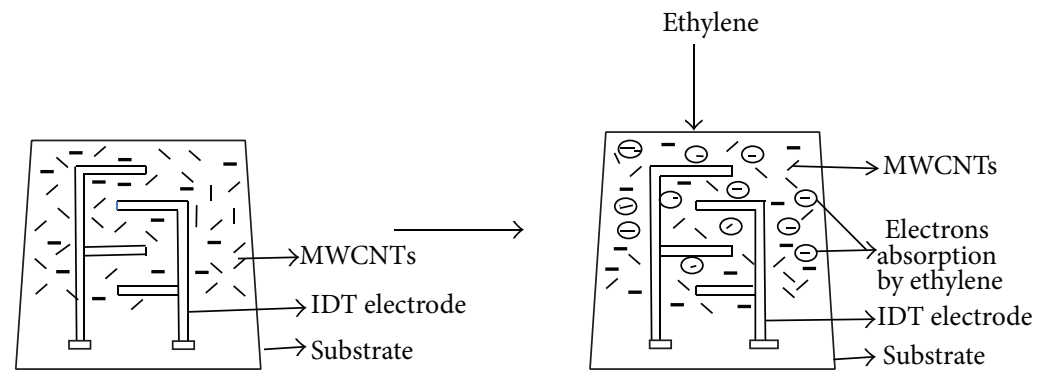

FIGURE 1: Schematic of ethylene detection by a chemoresistive sensor.

of gaseous molecules $\left(\mathrm{NO}_{2}, \mathrm{O}_{2}, \mathrm{NH}_{3}, \mathrm{~N}_{2}, \mathrm{CO}_{2}, \mathrm{CH}_{4}, \mathrm{H}_{2} \mathrm{O}\right.$, $\mathrm{H}_{2}$, and $\mathrm{Ar}$ ) involves either donation or withdrawal of electrons from the carbon nanotubes which can lead to a change in the resistance of the nanotubes $[15,16]$. The MWCNTs are made up of multiple layers unlike SWCNTs which further increases the surface to volume ratio and leads to high sensitivity towards gas sensing $[17,18]$.

Esser et al. [2] reported a reversible chemoresistive sensor for the detection of ethylene operating at room temperature with SWCNTs doped with copper (I) complex and observed a sensitivity of $1.8 \%$ (change in conductivity) for $50 \mathrm{ppm}$ ethylene concentration. Based on this work we explored the use of MWCNT in place of SWCNT (which is expensive) to sense ethylene and indeed are successful in developing MWCNT sensor for ethylene without any dopant. The basic working principle of our sensor element is increase in resistance on exposure to ethylene which is electron withdrawing [19]; the electrons are taken away from the CNTs as shown schematically in Figure 1 which leads to an increase in the resistance of the sensor. The increase in the resistance of the device is found to be proportional to ethylene concentration [2] interacting with CNTs.

\section{Experimental}

CNTs are characterized by FT-IR, Raman spectroscopy, and $\mathrm{X}$-ray diffraction.

2.1. Sensor Element Fabrication. The sensor element is fabricated by using ink-jet printing technology; it is a drop on demand printing technology and it is achieved by using piezo head based print head. It is a cost effective method of printing nanoparticles (conductive/ceramic) directly on the substrates either for developing electrodes or for depositing the conductive nanoparticles/semiconducting metal oxides/ceramic materials on the printed electrodes over the substrate $[20,21]$.

In our work we used Epson T60 Photo stylus commercial printer which is equipped with six cartridges and the printing can be done directly on any polyimide sheets. It has a provision for printing directly on planar alumina/glass substrates using linear translational printing technique apart from the conventional rotational printing technique.

Each nozzle cap has 90 nozzles and each nozzle size is $90 \mu \mathrm{m}$; the firing chamber inside the printer head is incorporated with a piezo electric wafer developed by MEMS fabrication technology at the top of the microink ejecting column.
When a printing command is generated, the electronic circuit produces a series of electric pulses which is fed to the piezo electric wafer; due to this the wafer undergoes a mechanical deformation and produces a small amount force on the ink stored inside the microink ejecting column. This force is used to eject a tiny drop of ( $3 \mathrm{pL})$ nanoconductive/ceramic inks from the ink ejecting column onto the printing surface as per the electrode/film pattern developed using AutoCAD.

Silver nanoparticles purchased from Sigma Aldrich, Germany, are converted into a silver nanoconductive ink with $20 \mathrm{wt} \%$ concentration with a viscosity of $7 \mathrm{cP}$ and surface tension of $35 \mathrm{dyn} / \mathrm{cm}$ as reported [20]. This nanoconductive ink is loaded in one of our printer cartridges and the IDT comb type silver electrodes are printed on the Kapton substrate. Kapton is a polyimide insulating material having excellent electrical, mechanical, and chemical properties, which can be used as an alternate for alumina/glass substrate and can be used up to $400^{\circ} \mathrm{C}$. It also has the unique advantage of flexibility and is ideal for various applications. Silver IDT comb type electrodes are printed with $1 \mathrm{~mm}$ line width and $2 \mathrm{~mm}$ interdigital electrode gap and with 20 microns thickness as shown in Figure 2(a). The carbon nanotube dispersion is applied onto the Kapton substrate printed with silver electrode through brush coating as shown in Figure 2(b). The solvent is evaporated by heating this substrate at $150^{\circ} \mathrm{C}$ for $3 \mathrm{~h}$.

2.2. Prototype Laboratory Setup. The schematic of the prototype laboratory setup for ethylene sensor using MWCNTs is shown in Figure 3. The MWCNT sensor element, gas test cell, ethylene generating chamber, potentiostat circuit, and data acquisition systems are developed by us and the reference ethylene sensor (amperometric) $\mathrm{C}_{2} \mathrm{H}_{4} / \mathrm{C}-200$ is bought from M/s Membrapore, Switzerland. The MWCNT ethylene sensor is enclosed in a test cell and the leads taken out of the test cell are connected to the potentiostat circuit. Its output is interfaced with PC loaded with LabVIEW software through Data Acquisition Module for data analysis. Ethylene gas is generated from the ethylene generating chamber in which fruits are kept and it is pumped to the test cell using peristaltic pump. Ethylene generated from the fruits is also passed to a reference ethylene sensor to estimate the ethylene concentration. This reference sensing element is also deployed with potentiostat circuit and data acquisition module to interface with PC loaded with LabVIEW software 


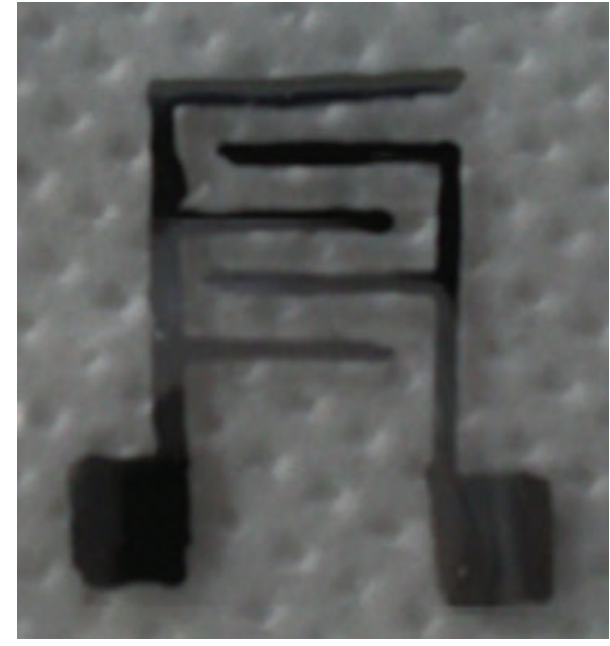

(a)

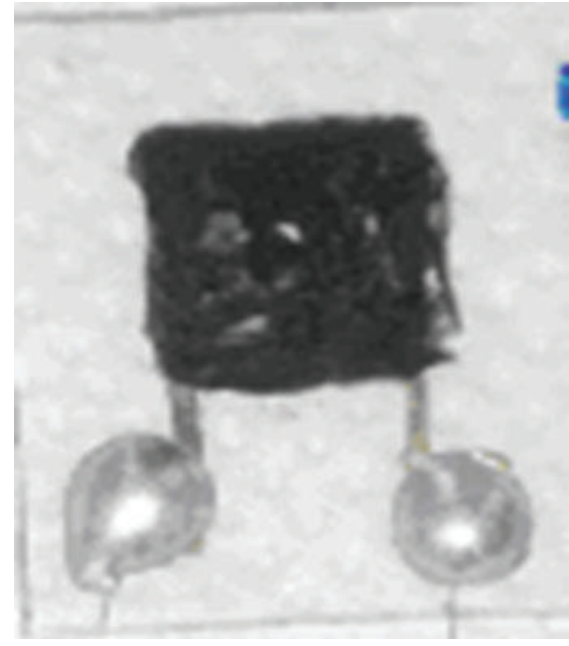

(b)

FIGURE 2: (a) Ink-jet printed silver IDT electrodes; (b) MWCNTs coated on the silver IDT electrodes.

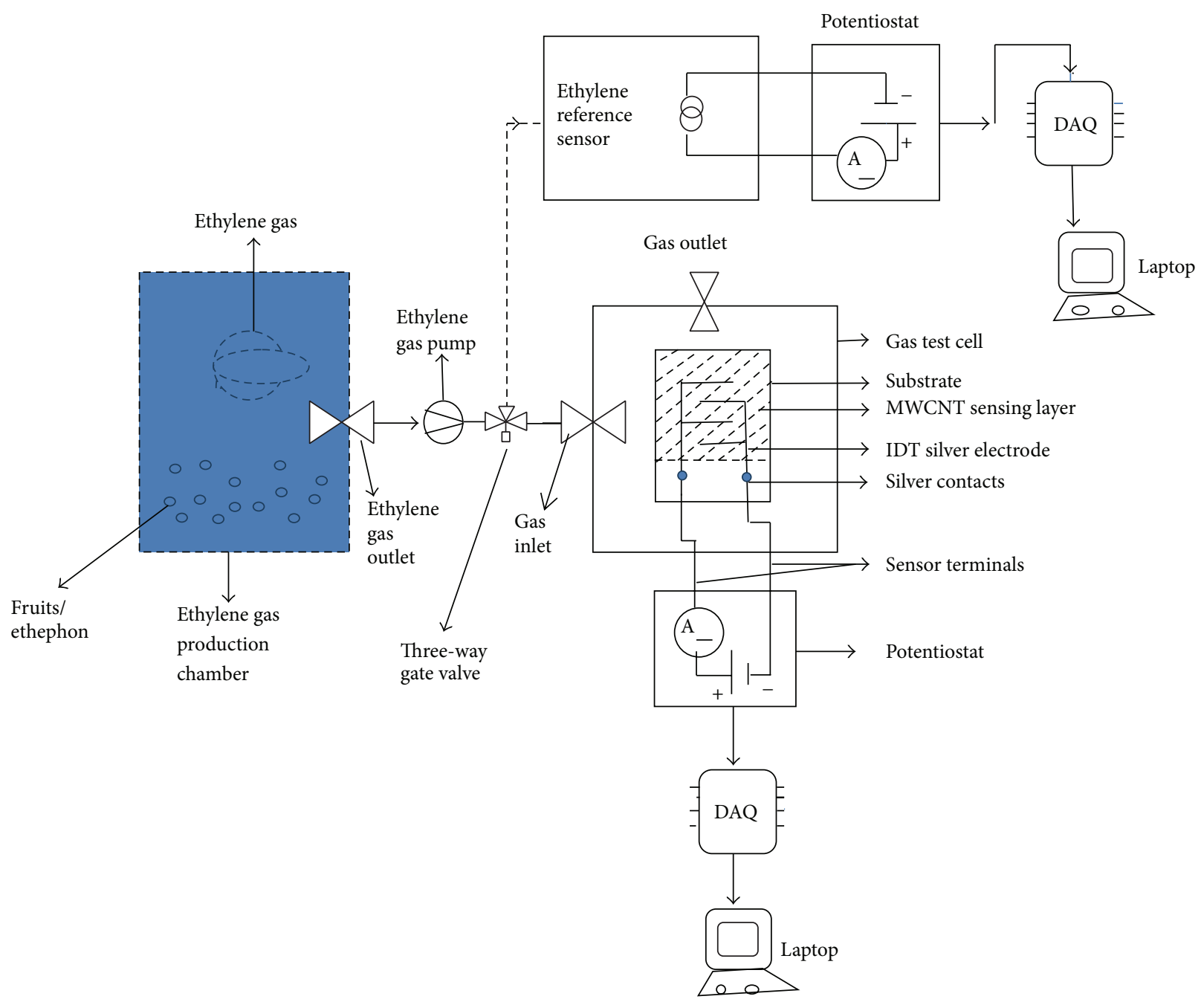

FIgURE 3: Schematic of the ethylene sensor laboratory setup. 


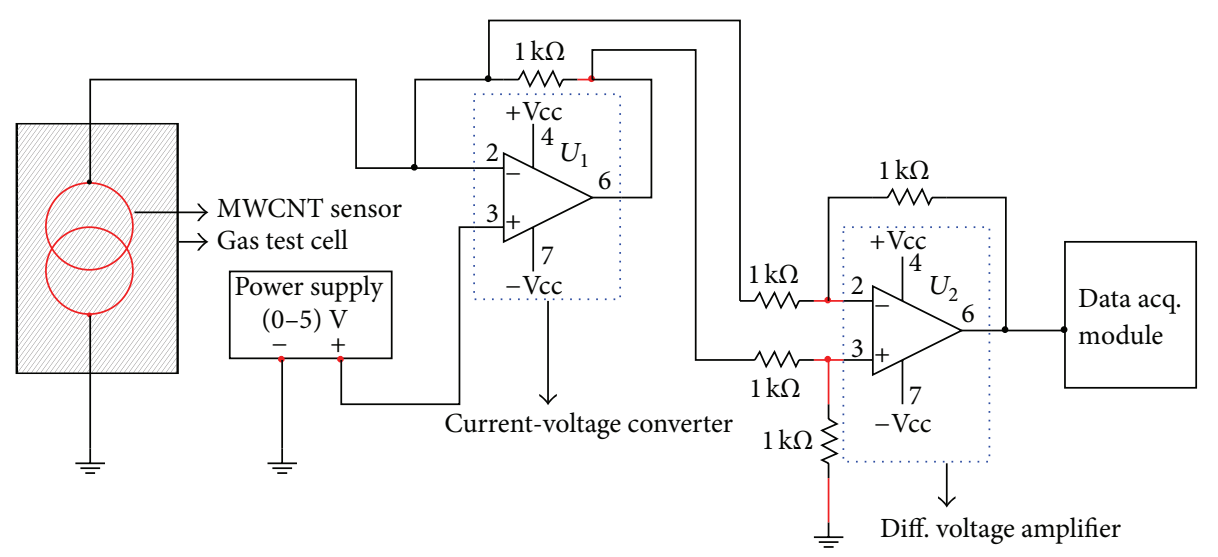

FIgURE 4: Potentiostat circuit for MWCNT ethylene sensor.

for data analysis and for conversion of intermediate signals into the gas concentration into ppm levels.

2.3. Potentiostat for Sensor. Potentiostat is the electronic integrated circuit used widely to feed the potential across the electrodes of the chemical cell and to collect the sensor response in terms of current during the sensing of the sensor. The potentiostat circuit used in our prototype laboratory setup for the ethylene sensor is given in Figure 4 . The potentiostat circuit comprises of current to voltage converter, difference voltage amplifier developed using high precision, and low offset and high gain instrumentation amplifier. The device is subjected to a potential difference of $2 \mathrm{~V}$ across the electrodes and the device current is converted into voltage by means of current to voltage converter and only the difference in the input signal is amplified through the difference voltage amplifier circuit.

2.4. Data Acquisition System for Sensor. The intermediate electrical signal obtained from the potentiostat circuit is interfaced with LabVIEW software loaded in a PC through 12-bit data acquisition module NI9201 of national instruments. The analog real world input is converted into the digital serial data of 12-bit resolution and transferred to the PC for processing and computation of gas concentration value based on the sensitivity of the sensing element. Current of the sensing element produced upon exposure to analyte is measured by the potentiostat circuit and the corresponding change in resistance of the sensing element is computed using the standard data acquisition system. The change in resistance related to the sensitivity is correlated to ethylene concentration.

2.5. Calibration of the Sensor. Our MWCNT sensor element is calibrated with precalibrated commercial ethylene gas of different concentrations bought from M/s Chemtron Science Laboratories Ltd, India. The precalibrated ethylene gas from the high pressure gas canisters is transferred into the gas sampling bags of Sigma Aldrich and a constant volume of ethylene gas is collected from the sampling bag by means of special gas collecting syringes and injected into the gas

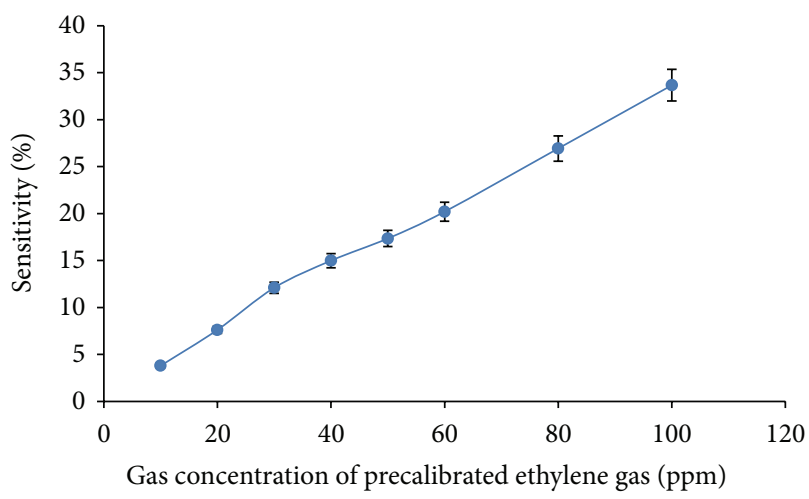

FIGURE 5: Calibration curve of MWCNT ethylene sensor.

test cell for its measurement by the MWCNT sensor. This experiment is repeated many times for each gas concentration and the repeatability of the readings is confirmed. The calibration curve of the MWCNT ethylene sensor is given in Figure 5. The sensitivity of the proposed sensor is calculated from the slope of the calibration curve. The calibration curve indicates linearity, sensitivity, and repeatability of the proposed sensor.

\section{Results and Discussion}

Ethylene gas released from fruits on natural ripening is collected in the gas chamber. The release of ethylene is confirmed using gas chromatography device Nucon 5765 which works on thermal conductivity detection principle. The sample chromatogram of ethylene gas sample measured by Nucon 5765 is given in Figure 6. The presence of a peak at a retention time of 30 seconds confirms the ethylene release during ripening process.

The prototype laboratory setup for ethylene gas sensor based on the MWCNTs is given in Figure 7. Ethylene gas is pumped into the gas test cell containing MWCNT sensor. This MWCNT sensor is a reversible chemoresistive type device which reacts with the target ethylene gas even at 


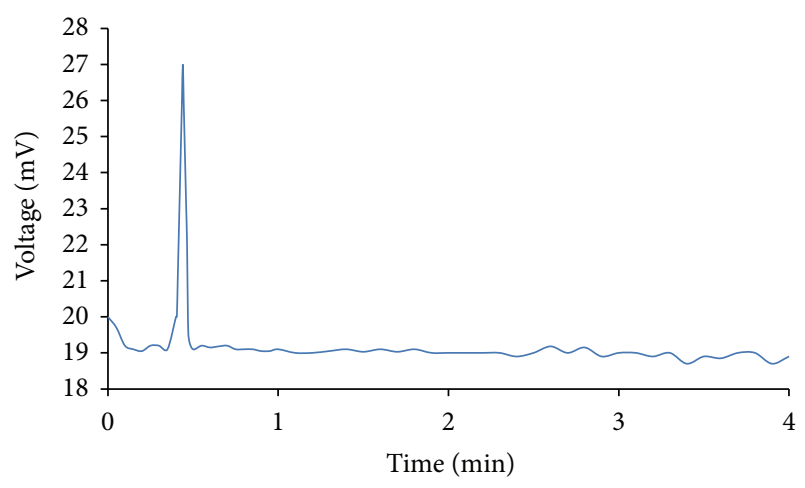

FIgURE 6: Gas chromatogram of ethylene gas sample.

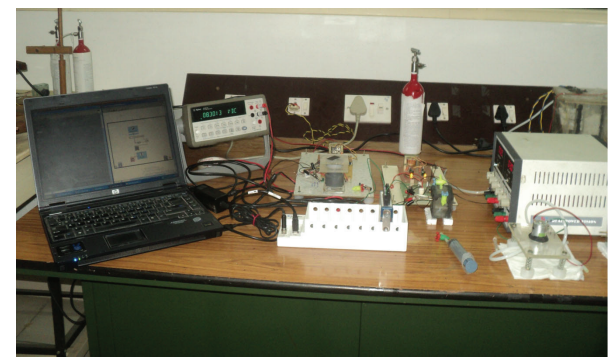

Figure 7: Prototype laboratory setup for ethylene sensor based on MWCNTs.

room temperature and the adsorption of ethylene leads to an increase of resistance of the sensor element.

Figure 8 represents sensitivity of MWCNT sensor as a function of concentration of ethylene. The sensitivity is expressed in terms of change in resistance of the sensor element in the presence and absence of the analyte and the formula is given below. The measurement was repeated and checked for its reproducibility. The reversibility of the sensor is in agreement with those reported earlier [2]. The percentage change in resistance of the sensor upon exposure to ethylene gas is calculated as follows:

$$
\text { Sensitivity }=\left(\frac{\Delta R}{R_{0}} \%\right)=\left(\frac{R_{\text {air }}-R_{\text {analyte }}}{R_{\text {air }}}\right) \times 100,
$$

where $R_{\text {air }} \rightarrow$ resistance of the device in air and $R_{\text {analyte }} \rightarrow$ resistance of the device exposed to analyte.

The sensitivity and linearity of the MWCNT sensor can be estimated from Figure 8. The proposed MWCNT sensor exhibits significant linearity over the measured range. The sensitivity per ppm of the sensor is $0.368 \%\left(-\Delta R / R_{0}\right) / \mathrm{ppm}$, the measurement carried out from $10 \mathrm{ppm}$ to $65 \mathrm{ppm}$ ethylene concentrations.

Table 1 confirms our sensor element based on MWCNT has a better sensitivity than the reported one based on SWCNT [2]. The response time (rise time and recovery time) of the MWCNT sensor was measured (for $20 \mathrm{ppm}, 30 \mathrm{ppm}$, and $50 \mathrm{ppm}$ ethylene concentrations) and it is found to be $10 \mathrm{~s}$ rise time and $60 \mathrm{~s}$ recovery time. Figure 9 represents the response of MWCNT sensor for the abovementioned concentrations.

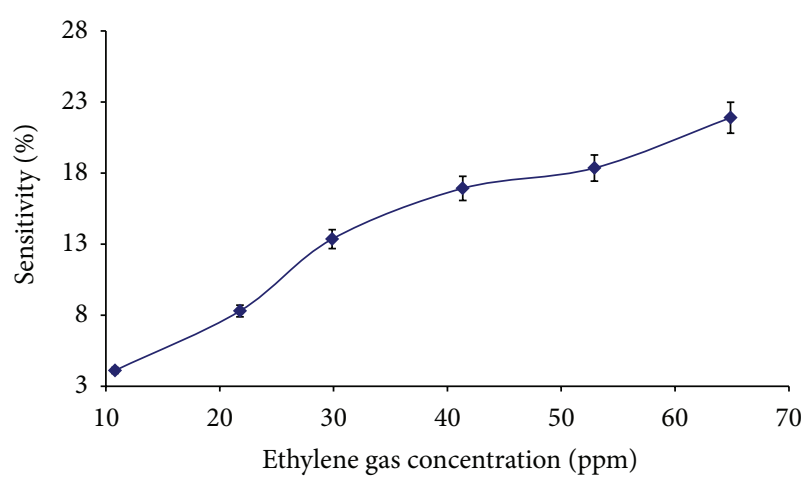

FIGURE 8: Sensitivity versus ethylene concentration.

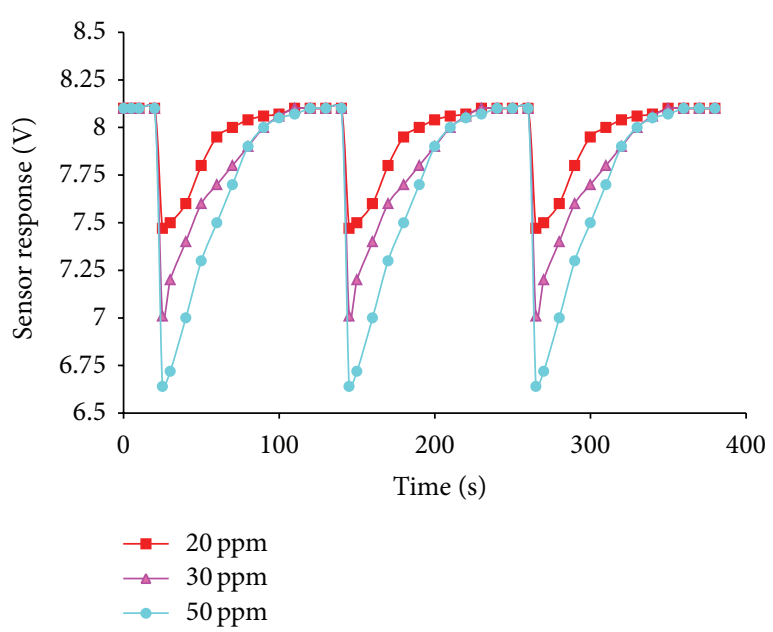

FIgURE 9: Response of MWCNT sensor with ethylene gas concentration.

TABLE 1: Sensitivity of MWCNT versus SWCNT sensors.

\begin{tabular}{lccc}
\hline $\begin{array}{l}\text { S. } \\
\text { number }\end{array}$ & $\begin{array}{c}\text { Ethylene gas } \\
\text { Concentrations } \\
\text { in ppm }\end{array}$ & $\begin{array}{c}\text { MWCNT } \\
\text { (present work) } \\
\text { Percentage change } \\
\text { in resistance (\%) }\end{array}$ & $\begin{array}{c}\text { SWCNT } \\
\text { (previous work [2]) } \\
\text { Percentage change } \\
\text { in conductance (\%) }\end{array}$ \\
\hline 1 & 20 & 8.3 & 0.9 \\
2 & 50 & 18.4 & 1.8 \\
\hline
\end{tabular}

\section{Conclusion}

The work describes a prototype laboratory setup based on MWCNTs for ethylene detection in ppm levels. The chemoresistive sensor element is based on multiwalled carbon nanotubes. It has a higher sensitivity than the reported single walled CNTs with good linearity and repeatability. As the sensing device is developed on the flexible Kapton substrate it makes the device so compact and of less weight and economical and also useful for miniaturization. The proposed prototype laboratory setup can be converted into a commercial ready-made product that is of low cost, is highly sensitive, and is portable device for detection of ethylene for on-site applications. 


\section{Conflict of Interests}

The authors declare that there is no conflict of interests regarding the publication of this paper.

\section{References}

[1] S. M. Cristescu, J. Mandon, D. Arslanov, J. de Pessemier, C. Hermans, and F. J. M. Harren, "Current methods for detecting ethylene in plants," Annals of Botany, vol. 111, no. 3, pp. 347-360, 2013.

[2] B. Esser, J. M. Schnorr, and T. M. Swager, "Selective detection of ethylene gas using carbon nanotube-based devices: utility in determination of fruit ripeness," Angewandte Chemie, vol. 51, no. 23, pp. 5752-5756, 2012.

[3] W. Dhillon and B. V. C. Mahajan, "Ethylene and ethephon induced fruit ripening in pear," Journal of Stored Products and Postharvest Research, vol. 2, no. 3, pp. 45-51, 2011.

[4] V. M. Schmidt and E. Pastor, "Adsorption and oxidation of acetylene and ethylene on gold electrodes," Journal of Electroanalytical Chemistry, vol. 376, no. 1-2, pp. 65-72, 1994.

[5] S. Iijima and T. Ichihashi, "Single-shell carbon nanotubes of 1nm diameter," Nature, vol. 363, no. 6430, pp. 603-605, 1993.

[6] P. M. Ajayan and O. Z. Zhou, "Applications of carbon nanotubes," Carbon, vol. 80, pp. 391-425, 2001.

[7] J. Li, Y. Lu, Q. Ye, M. Cinke, J. Han, and M. Meyyappan, "Carbon nanotube sensors for gas and organic vapor detection," Nano Letters, vol. 3, no. 7, pp. 929-933, 2003.

[8] C. Cantalini, L. Valentini, I. Armentano, J. M. Kenny, L. Lozzi, and S. Santucci, "Carbon nanotubes as new materials for gas sensing applications," Journal of the European Ceramic Society, vol. 24, no. 6, pp. 1405-1408, 2004.

[9] M. Arab, F. Berger, F. Picaud, C. Ramseyer, J. Glory, and M. Mayne-L'Hermite, "Direct growth of the multi-walled carbon nanotubes as a tool to detect ammonia at room temperature," Chemical Physics Letters, vol. 433, no. 1-3, pp. 175-181, 2006.

[10] I. Hafaiedh, W. El Euch, P. Clement, E. Llobet, and A. Abdelghani, "Multi-walled carbon nanotubes for volatile organic compound detection," Sensors and Actuators, B: Chemical, vol. 182, pp. 344-350, 2013.

[11] F. Mendoza, D. M. Hernández, V. Makarov, E. Febus, B. R. Weiner, and G. Morell, "Room temperature gas sensor based on tin dioxide-carbon nanotubes composite films," Sensors and Actuators B: Chemical, vol. 190, pp. 227-233, 2014.

[12] H.-Q. Nguyen and J.-S. Huh, "Behavior of single-walled carbon nanotube-based gas sensors at various temperatures of treatment and operation," Sensors and Actuators B: Chemical, vol. 117, no. 2, pp. 426-430, 2006.

[13] A. Firouzi, S. Sobri, F. M. Yasin, and F. Ahmadun, "Fabrication of gas sensors based on carbon nanotube for $\mathrm{CH}_{4}$ and $\mathrm{CO}_{2}$ detection," in Proceedings of the International Conference on Nanotechnology and Biosensors (IPCBE '11), vol. 2, pp. 165-168, Singapore, 2011.

[14] J. Li and H. T. Ng, "Carbon nanotube sensors: science and applications," in Encyclopedia of Nanoscience and Nanotechnology, $\mathrm{H}$. S. Nalwa, Ed., pp. 591-601, American Scientific, Valencia, Calif, USA, 2004.

[15] S. Peng, K. Cho, P. Qi, and H. Dai, "Ab initio study of $\mathrm{CNT} \mathrm{NO}_{2}$ gas sensor," Chemical Physics Letters, vol. 387, no. 4-6, pp. 271276, 2004.
[16] J. Zhao, A. Buldum, J. Han, and J. P. Lu, "Gas molecule adsorption in carbon nanotubes and nanotube bundles," Nanotechnology, vol. 13, no. 2, pp. 195-200, 2002.

[17] P. Samarasekara, "Hydrogen and methane gas sensors synthesis of multi-walled carbon nanotubes," Chinese Journal of Physics, vol. 47, no. 3, pp. 361-369, 2009.

[18] W. Al Sekhaneh and H. Dahmani, "Nanosized zinc oxide deposited on single wall carbon nanotubes composites for nitrogen dioxide-sensors in museums and art galleries monitoring," Mediterranean Archaeology and Archaeometry, vol. 14, no. 1, pp. 25-35, 2014.

[19] J. M. G. Cowie, Polymers: Chemistry and Physics of Modern Materials, Reprinted, Nelson Thornes, 2nd edition, 2001.

[20] H.-H. Lee, K.-S. Chou, and K.-C. Huang, "Inkjet printing of nanosized silver colloids," Nanotechnology, vol. 16, no. 10, pp. 2436-2441, 2005.

[21] S. B. Fuller, E. J. Wilhelm, and J. M. Jacobson, "Ink-jet printed nanoparticle microelectromechanical systems," Journal of Microelectromechanical Systems, vol. 11, no. 1, pp. 54-60, 2002. 

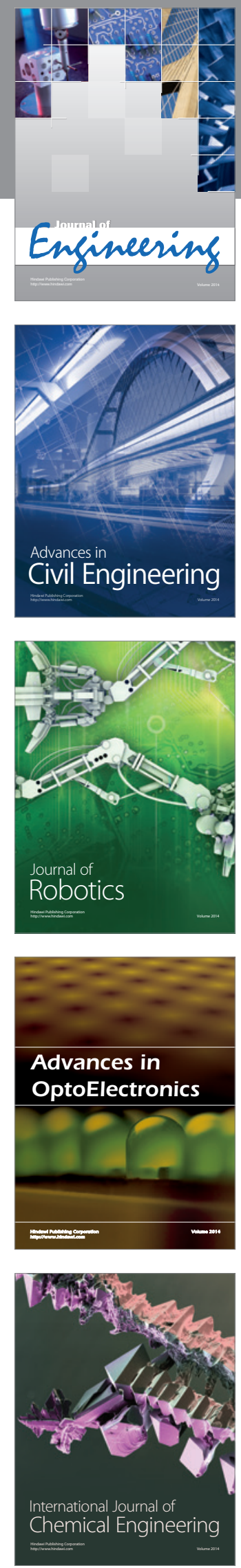

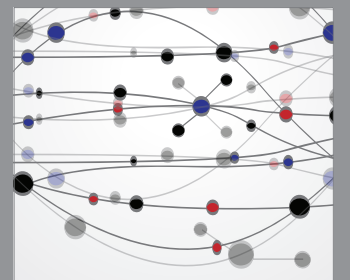

The Scientific World Journal


Submit your manuscripts at http://www.hindawi.com
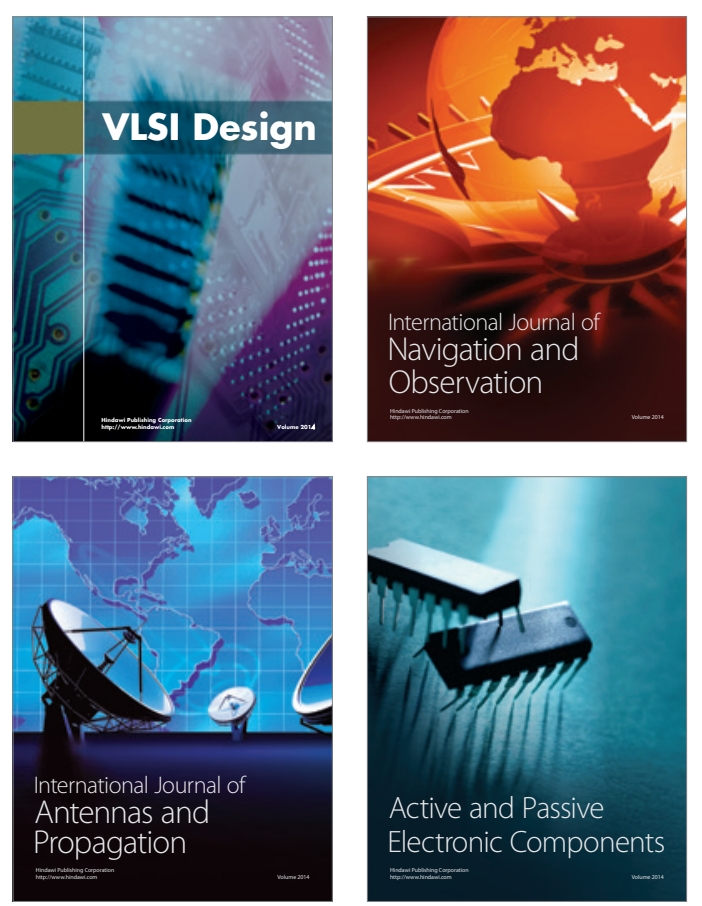
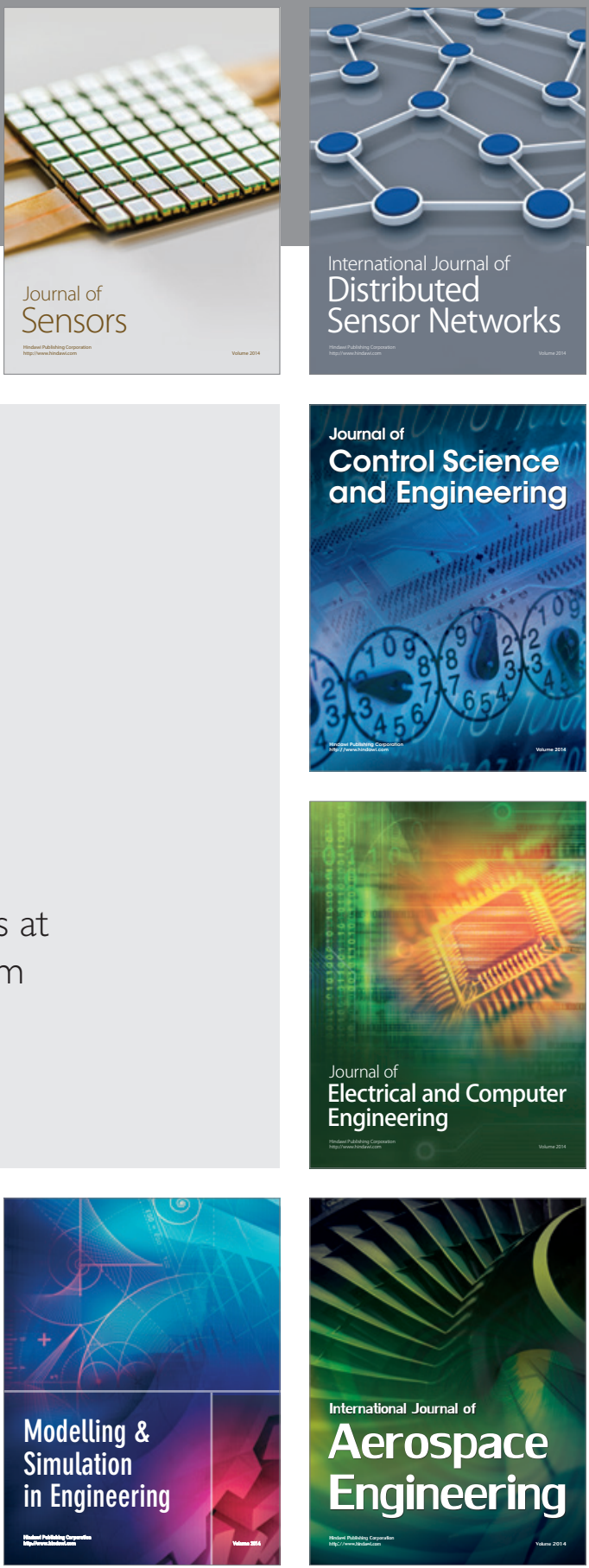

Journal of

Control Science

and Engineering
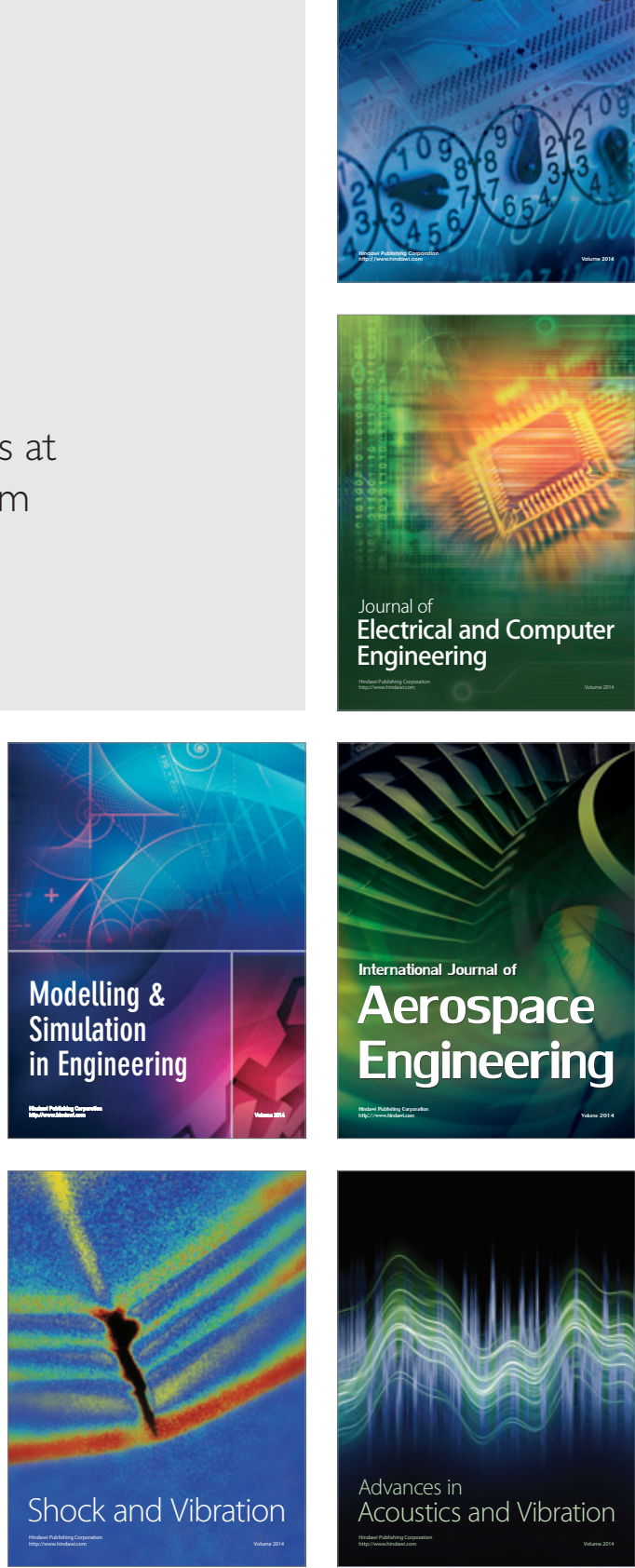